\title{
Barriers to women's occupational promotion to management levels
}

\author{
Jaefar Mamizade and Khadije Golabi*
}

Department of Management, Shoushtar Branch, Islamic Azad University, Shoushtar, Iran

CHRON I C LE ABSTRACT

Article history:

Received January 4, 2014

Accepted 1 June 2014

Available online

June 52014

Keywords:

Women management

Occupation

Organizational barriers

\begin{abstract}
This study examines the male and female employee's ideas about the organizational barriers to women's occupational promotion to management level in the organization of Education and Training in Khuzestan province. In this regard, with study of identified population, hypothesis was formulated and questionnaires with a five-item Likert scale and method of Cronbach's alpha reliability coefficient were adjusted. Questionnaires were distributed among 300 of employees, whose educations were beyond associate degree, including teaching and administrative staff. Due to incomplete or non-completion of questionnaires, statistical operations have been carried out on 288 questionnaires. Data were analyzed using SPSS software. The research method in this survey was descriptive in which all hypotheses, that had 0.05 level of significance, were confirmed. Finally, the results showed that there were relationships between institutional barriers and women's occupational promotion to management's levels. Furthermore, female staff had higher evaluation of the effect of organizational barriers to women's occupational promotion to management's levels than other group. Finally, practical suggestions and recommendations to promote women's occupation to management's levels were presented in this paper.
\end{abstract}

\section{Introduction}

During the past two decades, there has been an increasing trend on rate of educated women. They look for jobs and interested in participating in social, political, economic and cultural activities. Recently, some researchers have been interested in the issue of women's employment and obstacles in their vocational promotion. This has created motivation to investigate one of the critical issues in human resources, which is women's occupational promotion to management's levels in the organization of education and training in Khuzestan province located in south part of Iran. Presently, women are accounted as a significant portion of human resources of this province. In this regard, any investigation associated with occupational development and job promotion of this large group would be an interesting area of research. 
Wellington et al. (2003) performed an empirical investigation and explained that female manager's perception from barriers to women's progress was different from the male manager was. However, in a case of one factor, there was a consensus on it: $79 \%$ of female and the $90 \%$ of male staff believed that, lack of experience in general and executive management was a fundamental obstacle to women's promotion. They also presented another study over the period 1996-2003, by examining 1000 companies in which women's lack of experience in general or executive management, the informal women network; the stereotype of gender roles and lack of role models were the most important barriers to women's occupational promotion. Omar and Ogenyi (2004) investigated women's role in management in Nigeria and reported that there were stereotypes and negative evaluation about the female role in the society, and female's management was less favorable than male's. Therefore, with the existing severe discrimination, job promotion opportunities for women were limited. Jamali et al. (2005) performed an empirical investigation to find out more about constraints facing working women in Lebanon. In their study, pre- existing, traditional attitudes towards women's role and patriarchal culture were the most important barriers to women's occupational promotion to management's levels.

Weyer (2007) provided a theoretical explanation for the persistence of the glass ceiling keeping women from assuming leadership positions. He reported that both social role theory and expectation states theory belong to the structural/cultural models describing differences between the genders. In another study at the national level, Zahedi (2001) investigated a thesis entitled "Promoting women's participation in management's levels". The researcher conducted this comprehensive study with systematic approach, and considered the individual, organizational, and environmental dimensions in her study. She reported that, family responsibility's variables, organizational and cultural factors were the main reasons for the promotion of women to high levels of management. Fatemi Sadr (2002) performed an investigation to find the barriers on women's career promotion to management's levels at University of Tehran. In her research, cultural variables were the most important factors in women's prevention to reach to high levels of management. Individual factors were also effective, but their influences were less than cultural elements. Among the individual factors, personality traits had the most influence in preventing women to promote to high levels of management.

\section{The proposed method}

The statistical population of this research consists of all employees beyond associate degree (teachers and administrative staff) who have served in various regions in Khuzestan province. To select a representative sample of the studied population, 300 of employees were selected as sample members. Due to incomplete or non- completion of questionnaires, statistical operations have been carried out on 288 questionnaires. The study designs a questionnaire for evaluation of barriers to women's occupational promotion to management's levels (The Organization of Education and Training) and it has content validity. For providing valid questionnaire, a researcher has used the ideas of supervisor, advisor and specialists in this field. In this study, two methods of Cronbach's $\alpha$ (alpha) and bisection were used for determining the reliability of the questionnaire. The reliability coefficient of the questionnaire varies between 0.60 to 0.88 , which is generally indicate the acceptance of a coefficient. In our study, Cronbach's alpha was equal to 0.83 , which is well above the minimum acceptable level.

Questions concerning descriptive statistics (frequency, percentage and mean) and inferential statistics (uni-variate t-test, chi-square « $\chi 2 »)$ are used. Therefore, if frequencies related to the medium, high and higher options are more or less than low and lower frequencies, then this difference between the frequencies using the chi-square is significant (Khaki, 2005).

Research hypothesis: There is a significant correlation between organizational barriers and women's occupational promotion to levels of management 
Table 1 demonstrates the summary of frequency along with Chi-Square test associated with different questions of the survey.

\section{Table 1}

The summary of statistical observations

\begin{tabular}{|c|c|c|c|c|c|c|c|c|c|}
\hline \multirow[t]{2}{*}{ Questions } & \multirow[t]{2}{*}{ statistics } & \multicolumn{5}{|c|}{ options } & \multirow[t]{2}{*}{ mean } & \multirow{2}{*}{$\begin{array}{c}\text { Chi } \\
\text { square }\end{array}$} & \multirow{2}{*}{$\begin{array}{c}\text { Significance } \\
\text { level }\end{array}$} \\
\hline & & Very low & low & average & high & Very high & & & \\
\hline \multirow[t]{2}{*}{1} & abundance & 28 & 42 & 68 & 74 & 74 & 3.43 & 13.85 & 0.0001 \\
\hline & percent & 9.8 & 14.7 & 23.8 & 25.9 & 25.9 & & & \\
\hline \multirow[t]{2}{*}{2} & abundance & 15 & 29 & 54 & 68 & 117 & 3.86 & 110.9 & 0.0001 \\
\hline & percent & 5.3 & 10.2 & 19.1 & 24 & 41.3 & & & \\
\hline \multirow[t]{2}{*}{3} & abundance & 24 & 89 & 76 & 64 & 34 & 2.98 & 53.15 & 0.0001 \\
\hline & percent & 8.4 & 31 & 26.5 & 22.3 & 11.8 & & & \\
\hline \multirow[t]{2}{*}{4} & abundance & 21 & 55 & 90 & 71 & 48 & 3.25 & 46.77 & 0.0001 \\
\hline & percent & 7.4 & 19.3 & 31.6 & 24.9 & 16.8 & & & \\
\hline \multirow[t]{2}{*}{5} & abundance & 35 & 60 & 80 & 74 & 36 & 3.06 & 30.73 & 0.0001 \\
\hline & percent & 12.3 & 21.1 & 28.1 & 26 & 12.6 & & & \\
\hline \multirow[t]{2}{*}{6} & abundance & 32 & 60 & 91 & 61 & 42 & 3.07 & 35.5 & 0.0001 \\
\hline & percent & 11.2 & 21 & 31.8 & 21.3 & 14.7 & & & \\
\hline \multirow[t]{2}{*}{7} & abundance & 27 & 35 & 50 & 82 & 90 & 3.61 & 55.4 & 0.0001 \\
\hline & percent & 9.5 & 12.3 & 17.6 & 28.9 & 31.7 & & & \\
\hline \multirow[t]{2}{*}{8} & abundance & 25 & 40 & 85 & 80 & 56 & 3.36 & 45.92 & 0.0001 \\
\hline & percent & 8.7 & 14 & 29.7 & 28 & 19.6 & & & \\
\hline \multirow[t]{2}{*}{9} & abundance & 26 & 44 & 76 & 73 & 64 & 3.37 & 31.71 & 0.0001 \\
\hline & percent & 9.2 & 15.5 & 26.9 & 25.8 & 22.6 & & & \\
\hline \multirow[t]{2}{*}{10} & abundance & 13 & 46 & 72 & 89 & 66 & 3.52 & 59.21 & 0.0001 \\
\hline & percent & 4.5 & 16.1 & 25.2 & 31.1 & 23.1 & & & \\
\hline \multirow[t]{2}{*}{ Total } & abundance & 248 & 500 & 742 & 736 & 619 & 3.34 & 297.93 & 0.0001 \\
\hline & percent & 6.8 & 6.17 & 1.26 & 9.25 & 8.21 & & & \\
\hline
\end{tabular}

\section{The results}

As it can be observed in Table 1, for all the questions concerning the relationship between organizational barriers and women's occupational promotion to higher levels of management, frequency of options for medium to high and higher was greater than the frequency of moderate or low options. The difference between the frequencies is statistically significant $\left(p=0.0001\right.$ and $\chi^{2}$ =297.93). Therefore, the main hypothesis is confirmed. In other words, there is a significant correlation between the organizational barriers and women's occupational promotion to levels of management.

\section{Conclusion}

According to the results of hypothesis testing, there is a significant correlation between organizational barriers and women's occupational promotion to management levels ( $p=0.0001$ and $\chi^{2}=297.93$ ). Thus, the organizations are effective in women's promotion in their work. Each organization in order to succeed should use all its existing expertise and employees. There is no difference whether women have this expertise or men. It is needed to remove organizational barriers in the way of women's progress and promotion in their jobs and organizations should experience passing through the "glass ceiling". There is a significant correlation between negative attitude of the managers towards female manager and their occupational promotion to management's. Organizations should have a positive view towards women's abilities in order to pave the way for women in their promotion to higher levels of management. There is also a significant correlation between female's access to unofficial information network and their occupational promotion to management's. In other words, one of the important factors in women's job relating to promotion is their access to unofficial information networks. These informal information networks are effective factors in the organizational promotion. 
Access to information is a very fundamental and crucial factor in progress of all people, including women. When women are deprived of unofficial networks of information, their chance for obtaining managerial position will be reduced. Difference between male and female employee's evaluation of the effects of organizational barriers in job promotion is also another result of this survey. In other words, female employee had higher evaluation of the organizational barriers to women's occupational promotion to levels of management in compare with male employees.

There were also significant differences between married and single employee's evaluation about the effects of organizational barriers to female's job promotion. In other words, single employee had higher evaluation of organizational barriers to women's occupational promotion to levels of management in compare with married employee. It is worth mentioning that employees with 1 to 5 years of work experience had higher evaluation of the organizational barriers to women's occupational promotion to higher levels of management.

The organization's human resources system must consider two things: first, it should pay attention to female education in management skills, and for this purpose, a special training center to teach women to develop management skills should be established. In addition to management skills trainings, personality skills such as confidence, analytical and critical-thinking skills, macro views, ambition, independence and assertiveness should be taught to women. In this way, using qualified instructors and consultants with management experience in the education and rehabilitation of female employees should be considered. Through these specialized trainings, professional conduct is strengthened in women. Another suggestion to the department of human resources is that they should emphasize on meritocracy system and its application in a way that in recruitment, appointment, promotion, and career points, the criterion of meritocracy is only considered. Organization should not consider gender as an eliminating factor in their professional selection. Organizational environment must also acknowledge the presence of women in management positions. In order to achieve this purpose, organizations should not hesitate to offer challenging and executive positions to women. They should test women's management and use management consultants in their organization. Another suggestion is that all councils will be formed of the number of eligible women to increase the worthy representation of women on boards and committees.

\section{References}

Fatemi Sadr, F. (2002). Career promoting barriers for women in management levels at Tehran University. Faculty of Management, Technical report.

Jamali, D., Sidani, Y., \& Safieddine, A. (2005). Constraints facing working women in Lebanon: an insider view. Women in Management Review, 20(8), 581-594.

Jogulu, U., \& Wood, G. (2011). Women managers' career progression: an Asia Pacific perspective. Gender in Management: An International Journal, 26(8), 590-603.

Khaki, G.R. (2005). Research Methods, the approach to the dissertation. Tehran, Baztab Publication, $2^{\text {nd }}$ ed..

Omar, O., \& Ogenyi, V. (2004). A qualitative evaluation of women as managers in the Nigerian Civil Service. International Journal of Public Sector Management,17(4), 360-373.

Statistical Center of Iran. (2007). labor force indexes, Spring.

Wellington, S., Kropf, M. B., \& Gerkovich, P. R. (2003). What's holding women back. Harvard Business Review, 81(6), 18-19.

Weyer, B. (2007). Twenty years later: explaining the persistence of the glass ceiling for women leaders. Women in Management Review, 22(6), 482-496.

Zahedi, S. (2001). Promoting the participation of women in management levels. Reihaneh Publication, 3. 